\title{
Banks versus Markets. A Response to Kucinskas
}

\author{
Alexander Zimper*
}

April 14, 2016

\section{Introduction}

In Zimper (2013a) (=Z) I claim that the optimal allocation of the original Diamond and Dybvig (1983) (=DD) banking economy could be alternatively implemented through an intermediate asset market. This claim is apparently at odds with DD's classical rationale for the existence of banks as being welfare-superior to asset markets. In support of this supposed welfare-superiority of banks over markets, Kucinskas $(=\mathrm{K})$ has written a comment in which he states:

"The main result in Zimper (2013) is incorrect as it stands: laissez-faire equilibrium in the asset market is inefficient in the original Diamond and Dybvig environment. Without additional government intervention, the allocation characterized by Zimper is not a competitive equilibrium." (p. ...)

Apparently something has to give: Either my claim in $\mathrm{Z}$ is correct or, as $\mathrm{K}$ argues, it is incorrect. As it is, I stand by my claim. In hindsight, however, I should have made it clearer that the economy considered in Z is definitely not a "laissez-faire" economy in the sense of $\mathrm{K}$. Instead it is based on the implicit assumption that all agents in the economy commit to some ex ante investment decision before they would enter an ex post asset market (which does not necessarily mean "additional government intervention"). This implicit assumption corresponds to the implicit assumption in DD that all agents commit to their participation in the bank's demand deposit contract. While I thought that this

*Department of Economics, University of Pretoria, and Kiel Institute for the World Economy. Email: alexander.zimper@up.ac.za 
was obvious from my representative agent maximization approach, K's comment shows that it was apparently not. ${ }^{1}$

In what follows I give a more detailed argument about the issue at hand.

\section{Argument}

In this section I briefly recall the DD and the Z-approach, respectively, I discuss the implicit assumptions of both approaches, and I revisit K's criticism of my claim.

\subsection{The DD-approach}

In period 0 all agents on the unit interval commit to a bank deposit contract according to which interest rates for early withdrawals (in period 1) are set. In period 1 agents learn their liquidity desire types and either withdraw funds or leave them with the bank to share the proceeds of the bank in period 2. DD show that these interest rates can be chosen such that they maximize the ex ante (period 0) expected utility of any given agent in this economy.

\subsection{The Z-approach}

In period 0 all agents on the unit interval commit to hold a specific amount of assets versus cash. In period 1 agents learn their liquidity desire types and start trading on the period 1 (=intermediate) asset market. $\mathrm{Z}$ shows that the period 0 asset versus cash holdings can be chosen such that the period 1 asset market equilibrium maximizes the ex ante (period 0) expected utility of any given agent in this economy. The formal argument proceeds via a representative agent maximization problem such that marketclearing prices in period 1 are correctly anticipated in period 0 . In this sense, Z claims that intermediate asset markets can achieve the same welfare allocation as banks if market clearing prices are correctly anticipated.

\subsection{Implicit assumptions of both approaches}

Neither DD nor Z discuss the agents' implicit ability to commit in period 0, i.e., commitment to a participation in the demand deposit contract in DD, commitment to the

\footnotetext{
${ }^{1}$ Kucinskas writes: "Note that the analysis of Zimper becomes formally correct if we replace "representative agent" by "social planner" in the paper by Zimper." I was initially surprised that K felt that my analysis was in need of such semantic correction. But he might be right in that this point deserves some clarification.
} 
specific cash vs. asset holdings in Z. That this commitment assumption is crucial to the welfare-maximizing argument in both, DD and Z, can be seen when the period 0 situation is recast in a Nash equilibrium context:

1. Given that all other agents in DD have chosen the welfare-optimal demand deposit contract, any given agent has a strict incentive to deviate and become a "renegade" / "deviate" agent (here: investing all his cash in period 0 and sell the according assets in period 1 on an asset market to which the other (demand deposit) contract agents have access to). This argument has already been put forward by Jacklin (1987) (for a more formal approach compare Zimper 2013b).

2. Given that all other agents in $\mathrm{Z}$ have chosen the welfare-optimal asset and cash holdings, any given agent also has a strict incentive to deviate. For the reader's convenience, I derive in the Appendix the corresponding (symmetric) Nash equilibrium.

In other words, both the welfare-optimal allocations in DD and in Z cannot be established as Nash equilibria if there is no underlying commitment mechanism to participate in the demand deposit scheme of DD or to participate in the asset vs. cash holding scheme of Z, respectively.

\subsection{K's criticism revisited}

Whereas $\mathrm{Z}$ considers the period 0 maximization problem of a representative agent over the cash aggregate to determine the socially optimal period 0 cash and asset holdings for any agent, K's notion of a "laissez-faire competitive equilibrium" does not admit for any such representative agent. Although $\mathrm{K}$ does not model his approach within game theory, his "laissez-faire competitive equilibrium" amounts to the Nash equilibrium of Point 2 above (cf., the Appendix). K's criticism against the Z-approach is thus (in substance) analytically equivalent to Jacklin's (1987) criticism of the DD-approach which states that in a "laissez-faire economy with banking" the welfare-optimal demand deposit contract cannot be implemented. ${ }^{2}$

Given that the Z-approach is nothing else than the duplication of the DD demand deposit contract allocation through period 1 asset markets, it is quite obvious that the Jacklin critique can be equally applied to the Z-approach. If there is no commitment mechanism in $\mathrm{Z}$ (formally described in $\mathrm{Z}$ as the delegation of the individual choices in period 0 to the representative agent's choice), then the welfare-optimal allocation in

\footnotetext{
${ }^{2}$ By a "laissez-faire economy with banking" I mean an economy without any commitment mechanism that forces all people of the population to participate in the demand-deposit contract.
} 
Z cannot be established as a Nash equilibrium. Consequently, K's observation that a "laissez-faire competitive equilibrium" cannot establish the welfare-optimal DD (or, for that matter, the welfare-optimal Z) allocation is true but unsurprising.

When $\mathrm{K}$ criticizes my claim in Z, according to which banking is not (necessarily) superior to intermediate asset markets, he is, in my opinion, comparing apples to oranges: Whereas he accepts the implicit assumption of a non-laissez-faire economy in DD, he does not accept the implicit assumption of a non-laissez-faire economy in Z. ${ }^{3}$ In contrast, I try to compare apples to apples when I say the following:

Let us accept the implicit assumptions of the DD and the $\mathrm{Z}$ approach according to which all people commit (i) to the demand deposit contract in DD or to (ii) the specific cash vs. asset period 0 holdings in Z, respectively. Then the banking economy of DD as well as the intermediate market economy of $\mathrm{Z}$ result in the optimal welfare-allocation.

\section{Outlook}

Neither DD nor Z offer any explanation about the implicitly assumed period 0 commitment mechanisms which guarantee participation in either scheme. In other words, both approaches remain silent about the reason(s) why people should not deviate in period 0 from the proposed schemes. I agree with $\mathrm{K}$ that this open question is a weakness of my $\mathrm{Z}$ approach (as it is for the DD approach).

For my part I wished I had a good answer about relevant (either from a theoretical or from an empirical perspective) candidates for such commitment mechanisms. Of course, one can always consider a benevolent social planner who would, directly or indirectly, force all people to participate in either scheme. For example, a benevolent social planner who shuts down intermediary asset markets would indirectly force all people to participate in the DD demand-deposit contract: If there was no possibility of trading in a period 1 asset market, there would be no strategic incentive for becoming a "renegade" / "deviate" agent. K seems to favor this notion of direct or indirect government intervention whereby he refers in his Section 4 to interesting articles about investment taxation or/and regulatory liquidity requirements.

Alternatively, instead of calling for government intervention, one might consider a "capitalist" solution in which it pays to achieve the social optimum. Consider a metagame where either scheme becomes only implemented whenever all people in the pop-

\footnotetext{
${ }^{3}$ But I am happy that $\mathrm{K}$ makes in his revised version the following concession: "In this more limited sense, Zimper is correct in saying that banks are not better than markets." The "more limited sense" was all I was aiming at in $\mathrm{Z}$.
} 
ulation participate in the respective scheme. For example, suppose that the DD bank would only start working if all people joined its demand-deposit contract scheme. In a Nash equilibrium of this meta-game there will be no strict incentive for non-participation and the DD bank has itself catapulted into business. Similarly, the Z-approach could be implemented through the "equity shares scheme" described in Jacklin (1987, pp.30-31) where people pool their resources in an investment firm which they become shareholders of. ${ }^{4}$ In period 0 the shareholders would commit to a period 1 dividend payment which mimics the optimal cash holdings of the Z-approach so that equilibrium trade on the intermediate asset market for ex-dividend shares of the firm will result in the welfare-optimal allocation of the Z-approach. Again, if this firm would only start working whenever all people joined it as shareholders, there will be no strict incentive for non-participation and the investment firm has catapulted itself into business.

Is such a "capitalist" solution plausible? Why not. Recall that the welfare-optimal allocation in the DD and the Z-approach exploits the law of large numbers; that is, the "business plan" / "economic role" of a DD bank, or of a Jacklin investment firm for that matter, already requires sufficiently many participants to begin with. It looks therefore intuitively compelling that both schemes might only start working whenever a sufficiently large number of people are participating. To formalize this intuition within a proper game-theoretic model looks to me like an interesting avenue for future research. ${ }^{5}$

\section{References}

Diamond, D.W., and P.H. Dybvig (1983) "Bank Runs, Deposit Insurance, and Liquidity," Journal of Political Economy 91, 401-419.

Jacklin, C.J. (1987) "Demand Deposits, Trading Restrictions, and Risk Sharing", chap. II, p. 26-47 in Prescott, E.C., and N. Wallace [eds.] (1987), Contractual Arrangements for Intertemporal Trade, University of Minnesota Press: Minneapolis.

Jacklin, C.J. (1993) "Market rate versus Fixed Rate Demand Deposits," Journal of Monetary Economics 32, 237-258.

Kucinskas, S. (2016) "When Are Banks Better Than Markets? Comment on Zimper (2013)," Economics Letters

\footnotetext{
${ }^{4}$ Jacklin (1993) comes back to this "equity shares scheme" in the form of so-called "market rate deposits".

${ }^{5}$ Maybe one would have to look at economies with asymmetric Nash equilibria where not all people participate in either scheme. Or at economies with heterogenous agents who do not all have the same investment or/and trading possibilities. Or maybe one would have to consider a discrete number of players since, in the context of a continuum of players, even a small interval of participants allows for the exploitation of the law of large numbers. Or...
} 
Zimper, A. (2013a) "On the Welfare Equivalence of Asset Markets and Banking in Diamond Dybvig Economies," Economics Letters 121, 356-359.

Zimper, A. (2013b) "Optimal Liquidity Provision through a Demand Deposit Scheme: The Jacklin Critique revisited," German Economic Review 14, 89-107.

\section{Appendix}

K solves in his Section 3 for a so-called "rational expectations equilibrium". His analysis implies that an intermediate asset market does not improve welfare over the autarkic situation if the agents cannot commit in period 0 to a socially optimal investment decision. Because this straightforward insight is most easily derived as a symmetric Nash equilibrium within the formal framework of a period 0 investment game, I sketch below the according game-theoretic argument while using the notation of $\mathrm{Z}$.

Given the aggregate amount of money $C$, the period 1 asset market clears at equilibrium price $p^{*}$ if and only if

$$
p^{*}=\frac{(1-\tau)}{\tau} \cdot \frac{C}{(1-C)} .
$$

Note that in the market equilibrium all low patience types will only hold cash whereas all high patience types will only hold assets. More precisely, any low type will hold $C+(1-C) \cdot p^{*}$ units of cash and any high type will hold $1-C+\frac{C}{p^{*}}$ units of asset in the market equilibrium. Agent $i$ 's expected utility in period 0 given his cash choice, $C_{i}$, and the aggregate cash choices of all other agents, $C$, is then given as

$$
\begin{aligned}
E U\left(C_{i}, C\right)= & u\left(C_{i}+\left(1-C_{i}\right) \cdot p^{*}\right) \cdot \tau+u\left(R \cdot\left(1-C_{i}+\frac{C_{i}}{p^{*}}\right)\right) \cdot(1-\tau) \\
= & u\left(C_{i}+\left(1-C_{i}\right) \cdot \frac{(1-\tau)}{\tau} \cdot \frac{C}{(1-C)}\right) \cdot \tau \\
& +u\left(R \cdot\left(1-C_{i}+C_{i} \cdot \frac{\tau}{(1-\tau)} \frac{(1-C)}{C}\right)\right) \cdot(1-\tau)
\end{aligned}
$$

The period 0 investment situation. Suppose now that in period 0 agent $i$ chooses investment strategy $C_{i}$ in order to maximize the period 0 expected utility (1) given that C.

A symmetric Nash Equilibrium: Suppose that $C=\tau$. Then

$$
E U\left(C_{i}, C\right)=u(1) \cdot \tau+u(R) \cdot(1-\tau)
$$


so that agent $i$ is indifferent between all his strategies $C_{i} \in[0,1]$. Consequently, there exists a symmetric Nash equilibrium such that, for all $i$,

$$
C_{i}^{*}=\tau,
$$

which coincides with the autarkic situation. Moreover, it can be shown that there are no other (symmetric) Nash equilibria. 